\title{
SURGICAL MANAGEMENT OF OESOPHAGEAL FOREIGN BODY SYNDROME IN AN INDIAN RING-NECK PARAKEET
}

\author{
A. P. ROY ${ }^{1}$, A. K. MAJI ${ }^{1}$, P. MUKHERJEE*2, \\ S. K. NANDI ${ }^{1}$ AND MD. KAZEM ${ }^{1}$
}

${ }^{1}$ Department of Veterinary Surgery and Radiology, West Bengal University of Animal and Fishery Sciences, 37, K. B. Sarani, Kolkata-700 037, West Bengal, India

${ }^{2}$ Department of Veterinary Clinical Complex, West Bengal University of Animal and Fishery Sciences, 37, K. B. Sarani, Kolkata-700 037, West Bengal, India

\begin{abstract}
An Indian ring-neck parakeet (Psittacula krameri manillensis) of 1.5 years age was presented with a complaint of accidental engulfing of a rubber tube, being used for feeding by owner. Patient revealed no symptoms of choke, but radiograph showed right lateral displacement of trachea due to presence of foreign body in mid-oesophagus. This article represents the successful surgical removal of foreign body via oesophagotomy in Indian ring-neck parakeet.
\end{abstract}

Key words: Choke, Indian ring-neck parakeet, Oesophageal foreign body, Oesophagotomy, Rubber feeding tube

The parakeets meaning long tail, the smallest member of the parrot family, is actually the elegant feature of this bird. The Indian ring-neck parakeet (Psittacula krameri manillensis) is beautiful and proved to be good pets for those willing to provide ongoing obedience training (Fafard, 2014). Gastro-intestinal foreign body is common in animals and avian species (Evans et al., 1994). It has been reported in number of avian species such as; companion birds, poultry birds, ostriches, zoo and poultry birds (Christine et al., 2009). Gastrointestinal foreign bodies in birds are most commonly found in the oesophagus, crop, proventriculus and small intestines (Adamcak et al., 2000). Composition of foreign bodies can be wood, rubber, synthetic or natural fibers, feathers, stones, plastics and metal (Wagner, 2005). For untamed birds, foreign body generally looks like its feed, but for tamed or pet birds, along with large sized feed, it can be feeding tools too (Altman, 1992). Cited literature supports ingestion and lodgement of various types of oesophageal foreign bodies in various tamed birds like myna, goose and parakeet (Hayati et al., 2012).
An Indian ring-neck parakeet of 1.5 years age and $140 \mathrm{~g}$ weight was presented at Surgery OPD, Veterinary Clinical Complex, West Bengal University of Animal and Fishery Sciences, Belgachia with a complaint of accidentally engulfing a rubber tube, being used for feeding by owner. Though all clinical findings were in normal physiological range, patient was alert and no symptoms of choke like vomition, coughing, respiratory distress were noticed, it was advised for radiograph of cervico-thoracic region, ventro-dorsal view under anaesthesia (Injection ketamine hydrochloride at $50 \mathrm{mg} / \mathrm{kg}, \mathrm{I} / \mathrm{M}$ route was used as anaesthetic) to rule out the possibility of choking with kinked tube because of excitement. Radiograph showed right lateral displacement of trachea due to presence of foreign body in the oesophagus (Fig. 1). It was decided to remove the foreign body with forceps and moderate external manipulation through oral cavity under anaesthesia, but the non-surgical method proved to be unsuccessful, hence oesophagotomy performed immediately under same anesthesia. 
Indian Journal of Animal Health, June, 2020

Oesophageal foreign body in an Indian ring-neck parakeet

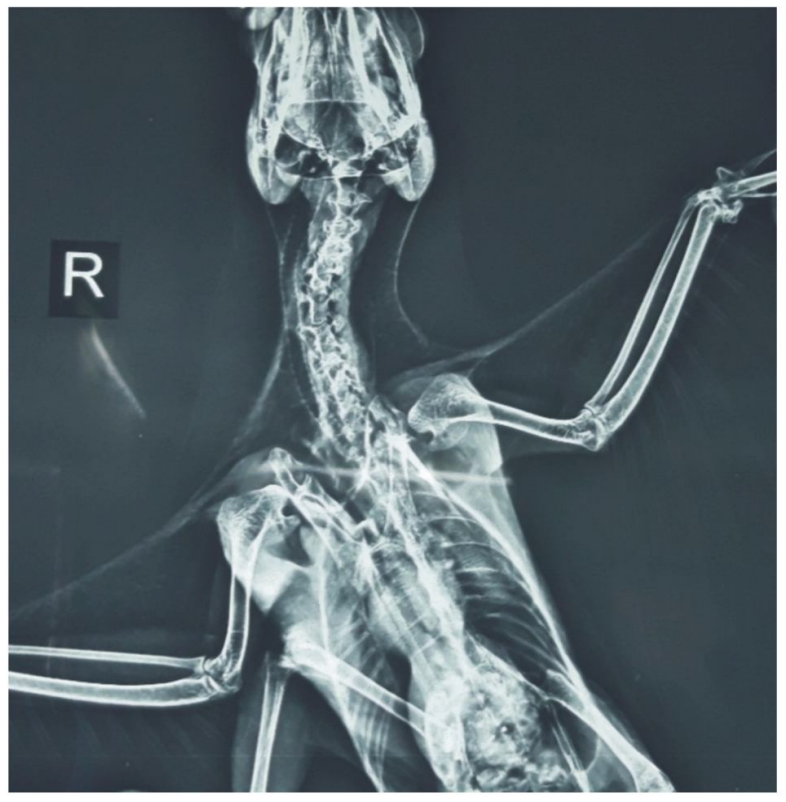

Fig. 1. Radiograph showing lateral deviation of trachea due to presence of radio-lucent foreign

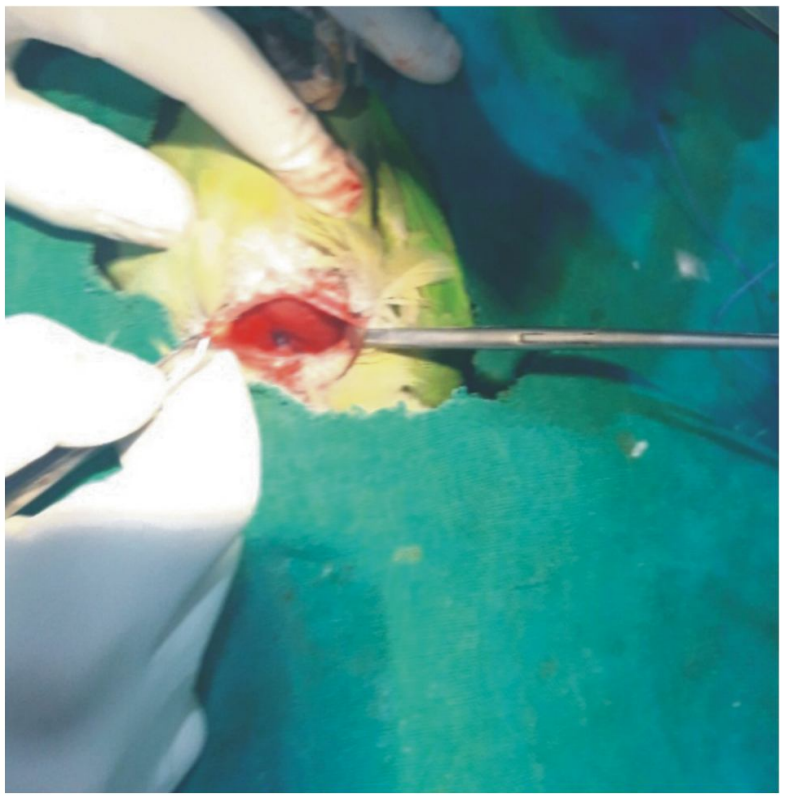

Fig. 2. Incision is being given for retrieval of foreign body

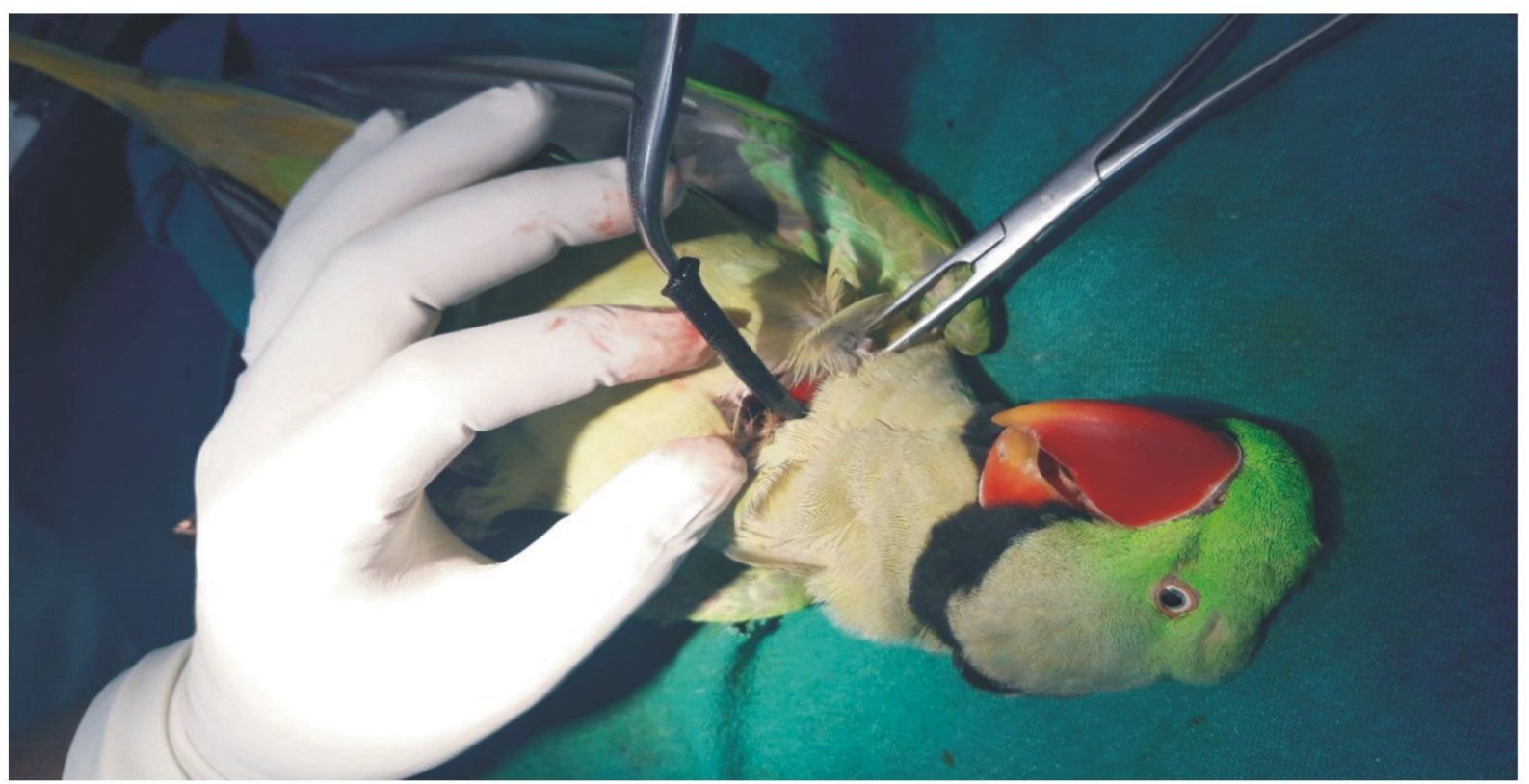

Fig. 3. Photograph showing surgical removal of foreign body through oesophageal incision 
Injection cefotaxime @ $50 \mathrm{mg} / \mathrm{kg}$ was applied via $\mathrm{I} / \mathrm{M}$ route to provide incisional-antibiotic coverage. Ventral cervical area was prepared aseptically, incised longitudinally cranial to the foreign body (Fig. 2). Oesophagus was isolated, incised a little and that rubber was removed with forceps (Fig. 3). Incised part of oesophagus was sutured in Lembert pattern using vicryl 4-0, following muscle and skin closure in a routine manner with absorbable and nonabsorbable synthetic suture accordingly keeping the birds under heating pads. Injection meloxicam at $0.2 \mathrm{mg} / \mathrm{kg}$ single $\mathrm{I} / \mathrm{M}$ dose was administered as analgesic. Strict dietary restriction with only liquid diet (glucose water, fruit juice, lentil soup) for at least 5 days and gradual introduction of normal food from $6^{\text {th }}$ day onwards was advised. Skin sutures were removed on $9^{\text {th }}$ day post operatively and the patient made an uneventful recovery.

Disposable silicone/rubber tubes work well to combat severe dietary deficits and assist feeding of young birds, but it may damage to crop wall as well. Presence of foreign bodies like feeding tube in the cage increases the risk of ingestion of foreign bodies (Fafard, 2014). Juvenile parakeets are very curious and frequently ingest foreign bodies such as cage substrate, feeding tubes, toys or whole seeds. This behaviour may be the result of their curious nature and their uncontrollable pumping for food (Altman, 1992). Associated conditions and disorders- anorexia,

\section{REFERENCES}

Adamcak A, Hess LR and Quesenberry KE, 2000. Intestinal string foreign body in an adult umbrella cockatoo (Cacatua alba). J Avian Med Surg, 14: 257-263

Altman RB, 1992. Avian neonatal and pediatric surgery. Seminar Avian Exotic Pet Medicine: 34-39

Bennett RA and Harrison GJ, 1994. Soft tissue surgery. In: Avian Medicine: Principles and Applications (Ritchie BW, Harrison HG, Harrison LR eds.). Lake Worth (FL), Wingers Publishing, pp10811095

Christine LM, Karyn LB and Brent H, 2009. Polyacrylamide gel ingestion leading to fatal intestinal obstruction in two birds in a zoological collection. J Avian Med Surg, 23: 286-289 depression, lack of faecal material, open beak breathing, dyspnoea and obstruction of GI tract can be seen in such cases. Three techniques including forceps in conscious birds, forceps in anesthetized birds and oesophagotomy were used for removal of the foreign bodies from oesophagus in parakeets. Using of any of these depends upon type of foreign body and its position (Bennett and Harrison, 1994). The less invasive method recommended first for extracting foreign bodies. So, in this case oesophagotomy was advocated after failing in removal of that foreign body via forceps introduction orally with moderate manipulation in throat region.

This article reports surgical removal of rubber tube as oesophageal foreign body after accidental ingestion. It might be life-threatening if choke occurs due to kinking inside or remain longitudinally inside decreasing the lumen diameter. Oesophageal choke may turn into oesophageal diverticulum due to the pressure created by the foreign body on oesophageal wall. Besides that, it may cause obstruction in crop making the case more complicated one. In this report, early diagnosis and proper surgical intervention was successful in retrieval of rubber tube, which acted as foreign body in oesophagus.

Conflict of interest: There is no conflict of interest regarding the present work.

Evans KL, Smeak DD and Biller DS, 1994. Gastrointestinal linear foreign bodies in 32 dogs: A retrospective evaluation and feline comparison. $\mathrm{J}$ Am Anim Hosp Assoc, 30: 445-450

Fafard A, 2014. Clinical veterinary advisor: Birds and exotic pets. Can Vet J, 55(12): 1179

Hayati F, Khafi MSA, SalmanzadehN, Lakzian A, Moghaddam AS et al., 2012. Surgical removal of a tube- like foreign body from an alexandrine parakeet (Psittacula eupatria) using a ventricular approach: A Case Report. Global Veterinaria, 9(6): 696-699

Wagner WM, 2005. Small intestine foreign body in an adult electus parrot (Eclectus roratus). J S Afr Vet Assoc, 76: 46-48

Received - 11.04.2020, Accepted - 19.05.2020, Published - 01.06.2020 